\title{
Exploration of Internationalized Education for the Graduate Student in Control Science and Engineering
}

\author{
Xin Yuan*, Zhiguang Feng, Lanyong Zhang and Lijun Yu
}

Harbin Engineering University, College of Automation, Harbin, China

*Corresponding author

\begin{abstract}
Internationalization is an inevitable trend for the development of higher education. It has become the consensus of the development of higher education in various countries to cultivate the top innovative talents with international competitive ability. As an example Harbin Engineering University was used to elaborate the cultivating pattern of internationalized talents in control science and engineering including the internationalized cultivating mode, the aspects of curriculum system, construction of teaching staff and expanding of internationalized exchange. This study is expected to provide the support for the internationalized education.
\end{abstract}

Keywords: International education, Postgraduate talent TRAINING, International exchange

\section{控制科学与工程学科研究生国际化人才培养模式探索}

\author{
原新*，冯志光，张兰勇，于立君
}

哈尔滨工程大学自动化学院, 哈尔滨, 黑龙江, 中国

“通讯作者

中文摘要

教育国际化是高等教育发展的必然趋势, 培养具有国际视野的创新人才已经成为各国高等教育发展的 共识。本文以哈尔滨工程大学为例, 从国际联合培养、国际化课程体系建设、师资队伍组成及拓宽学 生国际化交流等方面, 对控制科学与工程学科研究生国际化人才培养模式进行了实践和探索, 为相关 领域国际化人才培养提供支撑。

关键词：国际化教育；国际化人才培养；国际交流

\section{1. 引言}

研究生教育是培养高层次人才的途径之一, 也是高 等教育的重要内容。《国家中长期教育改革和发展规划 纲要 (2010-2020 年)》中明确指出, 国际化人才是为适 应国家经济社会对外开放的要求, 培养大批具有国际视 野、通晓国际规则、能够参与国际事务和国际竞争的国 际化人才。目前, 我国研究生的规模已达世界第一。但 是, 教育质量和学术素养是中国高等教育体系中相对薄 弱的环节, 与国际高水平仍然存在一定差距, 主要表现 在:

（1）国际化联合培养理念不够深入;

(2) 高水平国际化课程设置不足;

(3) 国际化教学模式有待改进;
（4）缺少国际化师资和与国外高水平学者交流的 学术平台。

(5) 研究生英语学术交流能力的欠缺

因此如何依托哈尔滨工程大学在船海领域的特色, 结合学科专业特点, 为船舶工业和国民经济建设培养具 有国际化视野及创新潜质的研究生是值得深入思考的 问题。

\section{2. 当前研究生国际化培养方向及需求分析}

具有国际化视野的研究生培养首先需要建立完善 的国际化教育机制。不断研究和分析全球范围内的国际 化教育, 汲取优秀先例的经验, 并结合本国实际情况, 指导高校开展相关工作。同时强化研究生质量管理，重 
视研究生培养在学术上的国际水准和学位上的国际质 量, 扩大我国研究生教育的优势和竞争力 [1-2], 加快 推进研究生国际化培养的进程。

其次需要创新培养目标理念, 改进研究生国际化培 养举措。要培养研究生的各项综合能力, 不仅包括创新 能力和科研能力, 还包括国际化视野下的学术思维和沟 通交流能力。因此, 研究生的培养目标要从多元内涵出 发, 采取搭建各类平台、课程/学术文化交流等有效措 施。

因此, 积极探索多元化的培养模式是高校目前应着 力去完成的任务之一。哈尔滨工程大学在控制科学与工 程学科国际化人才培养方面从国际化联合培养模式、建 设高水平国际化课程及教学科研团队等多角度进行探 索与实践。多样性的国际化教学模式, 使得研究生在国 内就能够跟踪国外最新发展动态、快速与国际接轨 [1-3]。鼓励研究生积极参加国际学术、科研合作项目, 有效地培养研究生的不同的思维习惯, 提高研究生的国 际交流能力, 适应国际竞争, 得到国际认同。

\section{3. 控制科学与工程学科国际化人才培养方案 的探索与实践}

\section{1. 加强国内外学术交流, 构建多层次国际 化联合培养模式}

国际学术交流在优秀博士硕士研究生的培养, 特别 是创新能力的培养方面起到了非常关键的作用。考察各 高校近些年来在学生国外访学、国际联合培养方面的实 践, 学院构建了多层次国际化联合培养模式, 其形式主 要包括以下几个方面:

（1）长周期项目：打造 “ $2+2$ ” “ $3+2$ ” 等联合培 养项目, 构建长周期国际化培养模式。选派优秀学生赴 国外高校开展联合培养, 通过国内和国际的衔接, 扩展、 深化和拓宽学生对相关领域的认知和理解, 使学生从不 同的教学和科研环境中受益。目前, 已有数名研究生申 请到了国家留学基金委资助的国家建设高水平大学公 派研究生项目, 到国外大学进行为期两年的联合培养博 士生学习, 有利地推动本专业人才培养国际化的渠道。

（2）中周期项目: 学生培养过程中实施至少一学 期的境外研修培养。学院与德国慕尼黑工业大学、英国 南安普顿大学、新西兰奥克兰大学、比利时根特大学、 美国威斯康星大学等建立海外合作培养基地, 选派优秀 学生赴国际高水平大学开展为期半年或十个月的境外 培养，进一步开拓和打造新的海外教育基地。

(3) 短周期项目: 深入开展短期境外研修项目, 拓宽学生国际交流渠道。利用暑期学校等短期研修项 目, 与国外高水平大学互派优秀学生参加教学及科研实 践活动, 接触和了解控制科学领域的前沿和动态, 拓宽 国际视野的同时也融入国际化的教学科研环境之中。每 年暑期, 学院都会迎来一批特殊的学员, 来自爱丁堡大 学的 20 余名本科生参加哈尔滨工程大学自动化学院举
办的为期 2 周的 “自动控制国际大学生暑期夏令营”。 他们在船舶导航与控制国家级实验教学示范中心进行 自动控制理论学习与实验、西门子 PLC 学习与实验、罗 克韦尔自动化系统学习与实验, 在人才培养方面进行了 深入的交流与合作。

\section{2. 建设高水平国际化课程，提高具有国际 视野的高素质复合人才的综合能力}

课程建设应以 “面向学科前沿、面向国际一流、面 向国家需求” 的教育理念, 将课程教学目标从 “坚实基 础” 的单一重心拓展到 “坚实基础、学科前沿、国际视 野”多元方向。

目前, 哈尔滨工程大学控制科学与工程专业已有多 门研究生课程进行双语或全英语授课, 并引用英文原版 教材。如研究生学位课《现代控制理论》、选修课《机 器人控制工程》等, 开阔了学生视野。既使本土学生受 益, 又能提高接收国际留学生的能力。

(1) 单门课程建设中, 加强课程教学内容、教学 模式和方法之间的融合与完善。

研究生阶段的教学, 有很大的探索性、开放性、包 容性, 应该更倾向于提高学生对知识的自我理解能力, 培养他们通过阅读文献总结掌握学科发展热点及未来 发展动向。鼓励学生通过组建课程小组、课后查阅资料、 课堂上进行汇报的模式进行理论课的学习。

推动现代信息技术与教育教学的深度融合, 在传授 理论知识的同时, 并行开展网络视频教学和演示教学探 索研究。基于网络的慕课课程突破了课堂授课的时空限 制, 以知识点为基本单元, 向学生提供更全面广泛的知 识内容, 激发学生的创新思维和创新能力。具体措施可 包括：(1)引入 “翻转课堂” 的理念, 建立小班研讨+翻 转课堂模式。(2)课程实施过程充分融合信息技术与国际 先进教学理念, 分享研究成果, 为师生交流、学生自主 交流提供便捷平台。(3)借助慕课平台建立 “教学共同 体”, 基于 “学习社区”, 教师深化教学知识, 推动教 学专业化。目前控制科学与工程的研究生学位课《随机 过程》、《现代控制理论》已完成了慕课录制工作，并 在学堂在线、中国大学慕课等平台上线运行, 专业课《组 合导航系统》等也在录制中。

（2）优化课程结构, 重视课程体系中课程之间的 整合与优化。

自动化学院遵循 “根据内、外部需求确定培养目 标, 根据培养目标确定毕业要求, 根据毕业要求确定知 识与能力要求及培养方式, 再反向设计课程体系” 的原 则, 以国际化高素质人才培养的毕业要求为依据, 设置 课程体系。优化课程结构, 加强课程之间的整合可以从 以下两个方面着手:

首先, 通过引入外方优质课程、增加选修课和跨学 科课程比例优化课程结构, 使其更具弹性、多样性和灵 活性, 满足学生个性化和多元化需求。其次, 通过课程 内容的渗透和互相补充加强课程与课程之间的整合创 新。 
（3）在整个培养模式中, 加强课程教学与科研训 练的协同整合。

坚持 “科教融合及学术育人” 理念, 优化教学内容, 实施 “推进式研究性教学”, 创新课堂模式。

“推进式研究性教学” 模式是指教师讲授一师生研 讨一学生探究的模式, 加强课程教学与科研实践的协同, 从而保障课程的活力与创新性。以现代控制理论课程建 设为例, 将该课程理论学习分为 “基础知识十热点问题 讨论” 两部分。除了讲授控制系统数学建模、系统的运 动分析、能控性与能观性等基础理论以外, 还要结合机 器人工程、船舶控制系统等研究热点, 设计有深度的问 题或案例, 在教学中引发学生积极思考, 培养研究生的 科研能力。为了实现控制科学与工程学科的人才培养目 标, 需要强化实践教学环节, 立足于教学大纲并且贴近 工程实际来设计综合性、创新型的平台实验。例如, 在 理论教学中引入倒立摆和三容水箱实验平台, 机械臂的 协调控制, 无人艇的轨迹跟踪等, 以提高研究生解决实 际工程问题的能力。

\section{3. 建设具有国际化视野的教学科研团队, 提高研究生培养质量}

高等教育的国际化首先体现在师资队伍的国际化, 国际化的师资队伍分为聘用外籍教师和培养本土教师 两个维度。聘用外籍教师特别是专业课外籍教师, 有利 于活跃学术氛围, 打破教学、科研等方面近亲繁殖带来 的诸多弊端, 为本土教师与外籍教师创设交流和合作平 台。健全教师出国交流的体制机制, 鼓励教师参加或主 动创造国外进修、短期培训或访问学者等学习机会, 打 造一支视野宽、专业强、素质高的国际化师资队伍。在 提高专业理论的同时, 也为教师提高英文水平提供了途 径, 从而提高专业课教师的全英/双语教学水平和双语 教学课程的授课效果。

目前, 学院已建设了多个教学科研团队, 各团队中 已有多名教师获得了资助出国进修访问, 这些教师回国 后可启动双语教学的建设和校级精品课的建设。其次, 要面向世界知名大学招聘人才。在引进人才时, 对于有 海外留学背景的控制科学与工程领域的人才优先录取, 这样能极大地改善教师的学缘结构, 增强学校的知名度 和国际化程度。

教学科研团队应将学术交流常态化, 在培养学生过 程中, 注重引导学生崇尚科学, 求真求实, 理论联系实 际, 引导和教育学生遵守学术道德规范。这种团队的研 究气氛会给学生潜移默化的影响, 让他们更多地了解到 科研工作的立项、研究重点, 项目实施中出现问题如何 解决等, 提高了学生的实践能力和创新性思维能力。

\section{4. 实施成效}

我校自动化学院聘请 “千人计划” 专家, 现任英国 纽卡斯尔大学教授、英国皇家工程院院士、国际电气电
子工程师协会院士 (IEEE Fellow) 、英国工程技术协会 院士 (IET Fellow) 乔纳森 - 钱伯斯教授为 “国际名誉院 长”。乔纳森 - 钱伯斯教授长期与我校在学术研究、博 士生和青年教师培养方面进行合作，十分关心并支持自 动化学院的发展。未来将参照世界一流大学信息学科建 设标准, 积极帮助自动化学院相关学科开展国际评估和 建设工作, 促进自动化学院国际化办学水平的进一步提 升。

借助学院每年组织召开的国际会议, 为自动化专业 的研究生提供与国际知名专家面对面交流的契机, 拓宽 学生的视野。近年来, 哈尔滨工程大学自动化学院与知 名高校和科研院所建立了长期合作关系, 如英国的纽卡 斯尔大学、南安普顿大学, 德国慕尼黑工业大学等。目 前, 已有数名研究生申请到了国家留学基金委资助的国 家建设高水平大学公派研究生项目, 到国外大学进行为 期两年的联合培养博士生学习, 推动了本专业人才培养 国际化的渠道。

\section{5. 结束语}

哈尔滨工程大学自动化学院一直致力于培养适应 社会与经济发展需要, 具有国际视野, 创新思维的控制 科学与工程、船舶控制工程领域的高级技术人才。培养 具有扎实的基础、宽阔的视野、较强的实践能力并且具 有国际化视野的高素质复合人才是我们不断追求的目 标。自动化学院研究生的培养亦以此为出发点, 并着重 培养学生的国际化视野与创新能力、团队协作和交流能 力、获取知识及终身学习能力等。

在研究生国际化培养推进的过程中, 不断探索和更 新理念, 使研究生国际化培养的目标更加清晰明确、课 程体系更加完善健全、师资队伍更大更强、教学模式丰 富多样、国际化交流与合作的渠道更宽更广，从而推动 国际化研究生教育水平达到新的高度。

\section{致谢}

本文为黑龙江省高等教育教学改革研究项目《大类 培养体系下学院多层次国际化人才培养模式探索与实 践研究》（SJGY20180089）、中国学位与研究生教育研 究课题《欧美一流大学研究生教育质量保证体系研究与 比较》（B-2017Y0504-075）、哈尔滨工程大学教学改 革研究项目《机器人工程专业拔尖创新人才培养的探索 与实践》（JG2019B07Z）的阶段性成果之一。 


\section{REFERENCES}

[1] Xiaorong Zhou, Jinquan Huang. Countermeasures and suggestions on the internationalization of Graduate students[J]. Jiangsu science and technology information, 2015, (1):44-46.

[2] Heng Yang, Jingyuan Wang. A study on the way of International cultivation of Graduate students[J]. University Education, 2016, (5):23-24.

[3] Hao Yang. Research on the International Training Mode of Postgraduate students in China at present[J]. Education of the times, 2017, (12):40-41. 